\title{
PENINGKATAN PRAKTIK KEBERSIHAN DIRI DAN LINGKUNGAN PADA POPULASI RENTAN: PRELIMINARY STUDY
}

\author{
Eviana Budiartanti Sutanto ${ }^{1}$ \\ Rafida Rahmasari ${ }^{2}$, Canggih Mugilaksana ${ }^{2}$, Stefany Mutiara Hastuti², \\ Altamirano Reza Pahlevi Handoko², Irine Kurnianingtyas ${ }^{2}$ \\ ${ }^{1}$ Program Fieldlab Fakultas Kedokteran UNIKA Soegijapranata, Semarang, Indonesia \\ ${ }^{2}$ Program Pendidikan Dokter Fakultas Kedokteran UNIKA Soegijapranata, Semarang, Indonesia \\ Korespondensi Penulis: \\ Nama $\quad$ : dr. Eviana Budiartanti Sutanto, M.Biomed \\ Alamat : Universitas Katolik Soegijapranata, Jl Pawiyatan Luhur Selatan IV No.1, Bendan \\ Duwur, Kec Gajahmungkur, Kota Semarang \\ Nomor Telepon : 08122929435 \\ Email : : eviana@unika.ac.id
}

\begin{abstract}
Abstrak
Latar belakang: Panti Asuhan adalah lembaga kesejahteraan sosial yang bertanggung jawab memberikan pelayanan kesejahteraan sosial pada anak terlantar termasuk kesehatan. Praktik kebersihan diri (personal hygiene) dan hidup sehat di panti asuhan masih perlu mendapat pendampingan melalui program promosi dan preventif.

Tujuan penelitian: Untuk menggali perilaku kebersihan diri; mengembangkan inisiasi intervensi untuk meningkatkan pengetahuan dan perilaku tentang praktik kebersihan dan kesehatan; mendeskripsikan reaksi anak-anak terhadap intervensi; dan mengukur perbedaan pengetahuan, perilaku dan hasil sesudah intervensi.

Metode: Jenis penelitian ini adalah preliminary study. Teknik sampling menggunakan purposive sampling dengan kriteria inkluasi adalah pengelola panti, penghuni panti yang sudah tinggal di panti minimal 1 tahun dan dapat berkomunikasi dengan baik, bersedia terlibat dalam proses intervensi yang dilakukan. Sedangkan kriteria eksklusi adalah penghuni panti yang tidak tinggal di asrama, dan yang tidak dapat berkomunikasi dengan baik. Teknik pengumpulan data menggunakan wawancara semi struktur. Data dianalisis secara deskriptif dan disajikan dalam tabel dan narasi.

Hasil: Penilaian luaran intervensi menunjukkan seluruh penghuni panti sudah bisa memahami pengertian mengenai pemilahan sampah organik-anorganik, $71,4 \%$ memahami tentang cara mencuci tangan yang benar sesuai enam langkah dan cara menggosok gigi yang benar. Terdapat $57,1 \%$ peserta yang memahami mengenai materi gizi seimbang dan $42,7 \%$ peserta paham akan bahan makanan sumber energi.

Kesimpulan: Edukasi dapat memberikan potensi perubahan perilaku. Walaupun penelitian ini bersifat sebagai penelitian pendahuluan (preliminariystudy), tetapi data yang diperolah dapat memberi input dan mapping bahwa intervensi perubahan perilaku di panti asuhan dapat ditingkatkan ke level penelitan yang lebih besar.
\end{abstract}

Kata kunci: personal hygine, gizi seimbang, panti asuhan

\section{Pendahuluan}

Kebersihan (hygiene) merupakan kebutuhan dasar setiap manusia. Tujuan ke-6 Sustainable

Development Goals (SDGs) menggarisbawahi akses ke sanitasi dan kebersihan yang memadai dan 
adil untuk semua, memberikan perhatian khusus pada kebutuhan perempuan, anak perempuan, dan mereka yang berada dalam situasi rentan seperti anak yatim piatu. ${ }^{(1)}$

Panti asuhan adalah suatu lembaga usaha kesejahteraan sosial yang mempunyai tanggung jawab untuk memberikan pelayanan kesejahteraan sosial pada anak telantar dengan melaksanakan penyantunan dan pengentasan anak telantar, memberikan layanan pengganti orang tua/ wali anak dalam memenuhi kebutuhan fisik, mental, dan sosial termasuk kesehatan. ${ }^{(2)}$ Kebersihan diri dan lingkungan di panti asuhan sering kali kurang mendapatkan perhatian, sehingga menimbulkan masalah kesehatan bagi penghuni panti. Keadaan ini dapat terjadi dikarenakan kurangnya praktik Perilaku Hidup Bersih dan Sehat (PHBS) oleh penghuni panti. Apabila praktik PHBS tidak diterapkan sebagaimana mestinya, akan mempengaruhi timbulnya berbagai gangguan kesehatan bagi penguhuni panti antara lain penyakit perut sepeti diare/ penyakit perut karena bakteri, penyakit kulit antara lain scabies, panu (Pitiryasis versicolor) dan tinea, status gizi yang kurang baik, gigi yang berlubang (caries) dan lain sebagainya. Gangguan kesehatan pada salah satu penghuni panti jika tidak segera ditangani dengan benar maka dapat berdampak/ menular pada penghuni yang lain. ${ }^{(3)(4)(5)}$

Berdasarkan pengamatan dan survei lokasi yang dilakukan pada bulan Maret 2021 di Panti Asuhan Eklesia, ditemukan bahwa fasilitas kebersihan dan praktik kebersihan diri secara umum masih rendah, seperti proses pembuangan sampah yang kurang higienis, penghuni panti yang jarang mengosok gigi, kurangnya konsumsi sayur-sayuran dan jarang mencuci tangan. Selain itu, ditemukan juga rendahnya kesadaran tentang menjaga kebersihan diri dan kamar.

Banyak penelitian menunjukkan dampak negatif kesehatan yang disebabkan oleh praktik kebersihan diri dan sanitasi yang buruk. Sebagai contoh peningkatan kejadian penyakit lebih tinggi terjadi pada mereka yang tinggal bersama di satu rumah dalam jumlah yang besar seperti halnya di panti asuhan. ${ }^{(6)}$ Walaupun demikian, saat ini belum banyak artikel yang menyajikan data terkait praktik kebersihan diri dan lingkungan di panti asuhan di Kabupaten Semarang. Keterbatasan ini tentu berdampak pada efektifitas intervensi kesehatan bagi penghuni panti asuhan. Hal ini karena suatu intervensi kesehatan membutuhkan informasi yang memadai tentang kondis populasi sasaran.

Penelitian ini menggambarkan dampak dari inisiasi upaya meningkatkan praktik kebersihan di kalangan penghuni panti di sebuah panti asuhan di Semarang, Indonesia dengan menggunakan desain preliminary study. Tujuan dari penelitian untuk mengukur pengaruh intervensi yang 
berbeda terhadap peningkatan praktik kebersihan di kalangan penghuni panti asuhan. Secara khusus penelitian berupaya menggali perilaku kebersihan pribadi; mengembangkan inisiasi intervensi pendidikan kesehatan untuk meningkatkan pengetahuan dan perilaku tentang praktik kebersihan; menggambarkan reaksi penghuni terhadap intervensi; dan mengukur perbedaan pengetahuan, perilaku dan hasil sesudah intervensi.

\section{Metode}

\section{Desain, Teknik Pengumpulan Data dan Analisis Data}

Jenis penelitian ini adalah preliminary study, yaitu studi pendahuluan yang dilakukan untuk menyempurnakan intervensi dan mengevaluasi akseptabilitas, kelayakan, biaya, dan penyerapannya. ${ }^{(7)}$ Teknik sampling menggunakan purposive sampling dengan kriteria inkluasi adalah pengelola panti, penghuni panti yang sudah tinggal di panti minimal 1 tahun dan dapat berkomunikasi dengan baik, serta bersedia terlibat dalam proses intervensi yang dilakukan. Sedangkan kriteria ekslusi adalah penghuni panti yang tidak tinggal di asrama, dan yang tidak dapat berkomunikasi dengan baik. Teknik pengumpulan data menggunakan wawancara semi struktur, dengan menyiapkan pertanyaan terlebih dahulu. Pertanyaan awal disusun berdasarkan gagasan-gagasan mengenai permasalahan yang sering dialami oleh panti asuhan. Pada pelaksanan wawancara, tetap dimungkinkan munculnya pertanyaan-pertanyaan baru untuk menggali lebih dalam informasi yang ada. Daftar pertanyaan wawancara dibagi dalam 5 bagian (profil panti asuhan, profil lingkungan panti asuhan, sanitasi panti asuhan, PHBS di panti asuhan, dan manajemen panti asuhan) yang keseluruhannya berjumlah 53 pertanyaan. Wawancara untuk mendapatkan data dilakukan kepada tiga orang penghuni panti (yang terdiri dari 1 pengurus panti dan 2 anak panti). Setelah mengidentifikasi kemungkinan permasalahan melalui wawancara, tahapan selanjutnya dilakukan observasi secara langsung. ${ }^{(8)}$ Metode observasi yang digunakan adalah observasi nonpartisipasi, dan saat observasi diketahui oleh penghuni panti, sehingga terjadi interaksi secara langsung dengan responden. Pada tahap ini, dilakukan pengamatan dan dokumentasi berupa foto di dalam ruangan panti maupun di lingkungan panti serta melakukan pencatatan hal-hal yang diperlukan untuk melengkapi data yang diperoleh. Dokumentasi foto diambil di kamar tidur, kamar mandi, ruang makan, dan dapur serta di lingkungan panti seperti halaman dan selokan/ tempat pembuangan air. Hasil dari wawancara dan pengamatan, kemudian dibuat pembobotan masalah dan didapatkan prioritas masalah pada panti asuhan yaitu pola makan 
yang belum sesuai dengan pedoman gizi seimbang, belum dilakukan cara mencuci tangan yang benar, secara keseluruhan penghuni belum mempraktikan cara menggosok gigi yang benar, serta kurangnya pemahaman dalam pengelolaan sampah organik-anorganik.

Analisis data dalam penelitian ini adalah analisis secara deskriptif, dimana peneliti hanya menyajikan data secara deskripif tentang profil praktik PHBS penghuni panti dan kebersihan lingkungan tempat tinggal. Selanjutnya hasil pengukuran luaran inisiasi intervensi edukasi kesehatan disajikan dalam bentuk deskriptif.

\section{Insiasi Intervensi: Edukasi Kesehatan}

Dalam penelitian ini, peneliti mengembangkan program intervensi untuk mengatasi masalah kesehatan yang ditemukan di Panti Asuhan Eklesia berjudul "Peningkatan Kesehatan Diri dan Lingkungan". Intervensi ini memiliki aktifitas berupa penyuluhan dan edukasi kesehatan dengan materi seperti pola makan sesuai dengan pedoman gizi seimbang, cara menggosok gigi yang benar, cara mencuci tangan yang benar sesuai enam langkah dan cara pemilahan sampah organik-anorganik. Pelaksanaan intervensi dilakukan secara online karena sedang kondisi pandemi dan dalam masa Pemberlakuan Pembatasan Kegiatan Masyarakat (PPKM) darurat. Pelaksanaan edukasi kesehatan secara online dilakukan pada periode bulan JuliAgustus 2021. Waktu yang diperlukan kurang lebih 2 jam, dengan jumlah peserta 10-15 orang. Selain melalui penyuluhan secara online, juga dilakukan pemasangan poster tentang cara membuang sampah, poster isi piringku, poster cara mencuci tangan, poster cara menggosok gigi yang benar dan tulisan-tulisan edukatif yang akan ditindaklanjuti setelah masa PPKM berakhir melalui kunjungan langsung ke panti asuhan. Dua minggu setelah intervensi, dibagikan lembar survei kepada ibu panti untuk mengukur perilaku anak panti setelah menerima edukasi dan pemahaman penghuni panti tentang materi edukasi yang disampaikan.

\section{Hasil}

\section{Karakteristik Demografi dan Lingkungan}

Panti Asuhan Eklesia terletak di Jl. Kartini No.12A Kelurahan Tambakboyo, Kecamatan Ambarawa, Kabupaten Semarang. Jarak antara panti asuhan dengan Universitas Katolik Soegijapranata sekitar $25 \mathrm{~km}$ dengan waktu tempuh 30-50 menit. Panti asuhan dihuni oleh 40 anak-anak (22 anak perempuan dan 18 anak laki-laki) dari berbagai pulau besar di Indonesia, dan 5 pengurus panti asuhan. Panti asuhan memiliki sejumlah ruangan yang cukup lengkap, meliputi 
6 kamar tidur (2 kamar untuk anak perempuan, 2 kamar untuk anak laki-laki, dan 2 kamar untuk anak berprestasi), 6 kamar mandi (4 kamar mandi perempuan, 2 kamar mandi laki-laki, 2 kamar mandi umum), 1 ruang ibadah, 1 ruang makan, 1 dapur, 1 ruang tamu, 1 ruang kostum, 1 perpustakaan, 1 kantor, 1 gudang, dan pos satpam. Terdapat kamar tidur sebanyak 6 buah yang terdiri dari Kondisi sanitasi panti asuhan telah menerapkan ketersediaan sumber air bersih berupa air kemasan untuk minum dan sumber air sumur dengan mata air terlindungi yang digunakan untuk mandi. Tipe jamban yang digunakan adalah jenis leher angsa jongkok.

\section{Profil Personal Hygiene dan Faktor Risiko}

Hasil kajian awal terhadap personal hygiene dan faktor resiko ditemukan bahwa kebiasaan sikat gigi yang belum sesuai karena hanya dilakukan 1 kali sehari yaitu di pagi hari; penghuni panti tidak selalu mencuci tangan dengan enam langkah, kamar tidur tidak tertata dengan rapih, serta belum melakukan pemilahan sampah organik dan anorganik. Namun, juga ditemukan praktik PHBS yang sudah sesuai dengan anjuran kesehatan seperti membuang sampah pada tempatnya, penghuni panti tidak ada yang merokok, buang air besar dilakukan di toilet, mandi minimal dua kali sehari, mencuci sprei, sarung bantal, dan selimut tiap satu bulan sekali, serta melakukan olah raga secara rutin. Dari sisi lingkungan tempat tinggal, sudah terdapat saluran air atau drainase dan pembuangan air limbah berupa selokan. Drainase digunakan untuk mengalirkan air dari fasilitas cuci tangan, kamar mandi, dan limpahan air hujan. Kondisi drainase/ saluran pembuang selalu dibersihkan sehingga air dapat mengalir dengan lancar. Hanya tersedia satu fasilitas cuci tangan menggunakan air mengalir, sabun cair, dan kain lap. Terdapat pula Tempat Pembuangan Sementara (TPS) dimana pengangkutan sampah dilakukan setiap 3 hari oleh petugas sampah lingkungan.

\section{Penilaian Luaran Intervensi}

Guna melihat manfaat dan faktor pendukung serta penghambat intervensi kesehatan yang dilakukan, maka dilakukan penilaian luaran intervensi yang meliputi pertanyaan mengenai perubahan perilaku yang terjadi setelah diberikan edukasi kepada penghuni panti. Sedangkan lembar survei untuk penghuni panti berisi pertanyaan seputar materi edukasi yang diberikan untuk menilai berapa tingkat penyerapan akan materi edukasi. Hasil penilaian luaran intervensi disajikan pada tabel 1 berikut. 
Tabel 1. Rangkuman Penilaian Luaran Intervensi

\begin{tabular}{|c|c|c|}
\hline Item pengukuran & $\begin{array}{r}\text { Tidak } \\
\text { pernah }\end{array}$ & Selalu \\
\hline $\begin{array}{l}\text { 1. Anak-anak panti menjaga kesahatan diri dan } \\
\text { lingkungan }\end{array}$ & & $\sqrt{ }$ \\
\hline $\begin{array}{l}\text { 2. Anak-anak panti melakukan cuci tangan } 6 \text { langkah } \\
\text { sesudah beraktifitas di luar }\end{array}$ & & $\sqrt{ }$ \\
\hline $\begin{array}{l}\text { 3. Anak-anak panti melakukan cuci tangan } 6 \text { langkah } \\
\text { sebelum makan }\end{array}$ & & $\sqrt{ }$ \\
\hline $\begin{array}{l}\text { 4. Anak-anak panti melakukan cuci tangan } 6 \text { langkah } \\
\text { sesudah ke toilet }\end{array}$ & & $\sqrt{ }$ \\
\hline $\begin{array}{l}\text { 5. Anak-anak panti melakukan cuci tangan } 6 \text { langkah } \\
\text { sebelum membantu menyiapkan makanan }\end{array}$ & & $\sqrt{ }$ \\
\hline $\begin{array}{l}\text { 6. Anak-anak panti menggosok gigi dengan cara yang } \\
\text { benar dan dengan frekuensi minimal } 2 x / \text { hari }\end{array}$ & & $\sqrt{ }$ \\
\hline $\begin{array}{l}\text { 7. Anak-anak panti makan sesuai jadwal yang telah } \\
\text { ditentukan pengurus panti }\end{array}$ & & $\sqrt{ }$ \\
\hline $\begin{array}{l}\text { 8. Anak-anak panti makan semua jenis makanan yang } \\
\text { disiapkan oleh pengurus panti }\end{array}$ & & $\sqrt{ }$ \\
\hline $\begin{array}{l}\text { 9. Anak-anak panti membuang sampah pada } \\
\text { tempatnya }\end{array}$ & & $\sqrt{ }$ \\
\hline $\begin{array}{l}\text { 10. Anak-anak panti melakukan pemilahan sampah } \\
\text { organik-anorganik }\end{array}$ & & $\sqrt{ }$ \\
\hline
\end{tabular}

Berdasarkan tabel 1, diketahui bahwa penghuni panti telah menerapkan PHBS sesuai dengan materi edukasi kesehatan yang diinisiasi oleh peneliti. Namun, analisis terkait dengan penyerapan materi edukasi yang telah diberikan sebagai mana disajikan pada tabel 2 menunjukkan bahwa seluruh peserta memiliki respon yang sesuai pada saat peneliti menanyakan umpan balik tentang pengelolaan sampah di lingkungan panti. Sebagian besar penghuni panti telah memahami materi mengenai cara mencuci tangan yang benar sesuai enam langkah dan materi frekuensi menyikat gigi yang benar. Sedangkan dalam hal penyerapan materi gizi seimbang masih rendah. 


\section{Tabel 2. Persentase Penyerapan Materi Edukasi oleh Peserta}

\begin{tabular}{lcc}
\hline \multicolumn{1}{c}{ Item pengukuran } & $\begin{array}{c}\text { Respon sesuai } \\
(\boldsymbol{\%})\end{array}$ & $\begin{array}{c}\text { Respom tidak sesuai } \\
(\boldsymbol{\%})\end{array}$ \\
\hline $\begin{array}{l}\text { 1. Prosedur cara mencuci tangan yang benar } \\
\text { sesuai enam langkah }\end{array}$ & $71,4 \%$ & $28,6 \%$ \\
\hline 2. Frekuensi sikat gigi yang benar & $71,4 \%$ & $28,6 \%$ \\
\hline 3. Penggolongan sampah organik & $100 \%$ & $0 \%$ \\
\hline 4. Penggolongan sampah non organik & $100 \%$ & $0 \%$ \\
\hline 5. Pedoman gizi seimbang & $57,1 \%$ & $42,9 \%$ \\
\hline 6. Pengertian bahan makanan sumber energi & $42,9 \%$ & $57,1 \%$ \\
\hline
\end{tabular}

\section{Diskusi}

Hasil identifikasi masalah didapatkan 4 permasalahan mengenai praktik personal hygiene di panti asuhan yaitu pola makan yang belum sesuai dengan pedoman gizi seimbang, belum mencuci tangan dengan benar sesuai enam langkah, praktik menggosok gigi belum dilakukan dengan benar, serta belum terdapat pengelolaan sampah organik-anorganik. Permasalahan dalam penerapan personal hygiene atau yang sering disebut PHBS tersebut dapat memberikan dampak kesehatan lebih lanjut antara lain, pertumbuhan dan perkembangan yang terganggu, rentan terhadap penyakit misalnya diare akibat infeksi, karies gigi dan penyakit akibat vektor (lalat, tikus, kecoak etc) akibat pengelolan sampah yang kurang baik. ${ }^{(9)(10)(11)}$ Untuk mengendalikan permasalahan tersebut, dilakukan edukasi materi kesehatan yang diprioritaskan adalah pola makan sesuai dengan pedoman gizi seimbang, cara menggosok gigi yang benar, cara mencuci tangan yang benar sesuai enam langkah dan cara pemilahan sampah organik-anorganik.

Permasalahan pada pola makan yang terjadi pada anak panti adalah masih adanya anak yang tidak mengkonsumsi sayur atau buah. Hal ini tidak sesuai dengan pedoman gizi seimbang "Isi piringku" yaitu panduan gizi seimbang yang didalamnya berisi pedoman dalam 1 piring berisi $1 / 3$ bagian makanan pokok, 1/3 bagian sayur dan 1/3 bagian lauk dan buah, disertai cuci tangan sebelum makan, aktifitas fisik 30 menit dan minum air putih 8 gelas sehari. Kebiasaan kurang mengkonsumsi sayur pada anak-anak akan berakibat kurangnya asupan mikronutrien dan serat yang akan berakibat selain gangguan pada tumbuh kembang juga secara langsung pada 
gangguan pencernaan seperti sembelit. ${ }^{(12)}$

Kebiasaan mencuci tangan dan menggosok gigi yang kurang benar pada anak panti yaitu sebagian anak tidak mencuci tangan sesudah beraktifitas di luar rumah dan mereka yang mencuci tangan tidak mengikuti pedoman cara mencuci tangan yang benar sesuai enam langkah dan kebiasaan menggosok gigi dengan cara yang kurang tepat serta frekuensi yang kurang dari 2 kali sehari. Hal ini dapat meningkatakan resiko terkena penyakit akibat infeksi baik infeksi saluran cerna, infeksi saluran napas dan penyakit gigi dan mulut. ${ }^{(13)}$

Jumlah tempat sampah yang disediakan di panti asuhan sudah cukup, serta kebiasaan membuang sampah juga sudah dilakukan sebagian besar penghuni panti. Namun pembuangannya belum dipisahkan antara sampah organik-anorganik. Apabila diterapkan dengan baik, kebiasaan memilah sampah akan memudahkan daur ulang samapah, mencegah polusi dan untuk sampah plastik dapat bernilai ekonomis. Bagi penghuni panti asuhan, kebiasaan memilah sampah bermanfaat sebagai latihan agar kedepannya mereka dapat menerapkannya di masa depan. ${ }^{(14)}$

Penelitian ini memiliki beberapa keterbatasan seperti jumlah responden yang tidak representatif, pengukuran luaran intervensi hanya dilakukan melaui formulir dan tidak tersedianya data variabel lain yang berhubungan dengan praktik personal hygiene oleh penghuni panti. Untuk mengatasi keterbatasan tersebut peneliti telah melakukan beberapa strategi seperti responden dipilih dengan kriteria inklusi sehingga kualitas informasi dapat dipercaya, melakukan cross tabulation untuk mengukur potensi recall bias. Walaupun penelitian ini bersifat pendahuluan namun dari hasil feedback yang diperoleh, terdapat perubahan perilaku ke arah yang lebih baik pada penghuni panti dalam hal kebiasaan makan, kebiasan mencuci tangan dan menggosok gigi serta pemilahan sampah. Hasil feedback yang didapat tentang penerimaan materi edukasi yang diberikan, $100 \%$ penghuni panti sudah bisa memahami pengertian mengenai pemilahan sampah organik-anorganik, 71,4\% memahami tentang cara mencuci tangan yang benar sesuai enam langkah dan cara menggosok gigi yang benar. Terdapat 57,1\% peserta yang memahami mengenai materi gizi seimbang dan $42,7 \%$ peserta paham akan bahan makanan sumber energi. Kurangnya pemahaman akan materi gizi seimbang khususnya mengenai bahan makanan sumber energi kemungkinkan karena meteri tersebut masih baru, belum banyak disampaikan dan disampaikan dalam waktu yang singkat. Dari umpan balik ini dapat menjadi masukan agar materi eduksi 
pedoman gizi seimbang khususnya tentang macam-macam bahan makanan dapat diberikan kembali agar penghuni panti lebih paham tentang materi tersebut.

\section{Kesimpulan}

Penelitian ini menunjukkan bahwa edukasi kesehatan dapat memberikan potensi perubahan perilaku. Walaupun penelitian ini bersifat sebagai penelitian pendahuluan (preliminary study), tetapi data yang diperolah dapat memberi input dan mapping bahwa intervensi perubahan perilaku di panti asuhan bisa ditingkatkan ke level penelitan yang lebih besar.

\section{Persetujuan Etik}

Penelitian ini tidak meggunakan persetujuan etik karena merupakan penelitian pendahuluan.

\section{Ucapan Terima Kasih}

1. Ucapan terima kasih kepada pengelola dan penghuni panti Panti Asuhan Eklesia yang telah bersedia berpartisipasi dalam program fieldlab FK UNIKA dan kesediaannya menjadi responden dalam penelitian ini.

2. Ucapan terima kasih kepada Program Pendidikan Dokter Fakultas Kedokteran UNIKA Soegijapranata yang telah memfasilitasi jalannya penelitian.

3. Ucapan terima kasih untuk Koordinator dan Tim Fieldlab FK UNIKA Soegijapranata

\section{Daftar Pustaka}

1. Widyasari V, Widyasari V, Prabandari YS, Utarini A. Training intervention to improve hygiene practices in Islamic boarding school in Yogyakarta, Indonesia: A mixed-method study. PLoS One. 2020;15(5 May):1-13. http://doi.org/10.1371/journal.pone.0233267

2. Kementerian Sosial Republik Indonesia. Peraturan Menteri Sosial Republik Indonesia Nomor : 30/HUK/2011 tentang Standar Nasional Pengasuhan Anak Untuk Lembaga Kesejahteraan Sosial Anak. Menteri Huk Dan Hak Asasi Mns Republik Indones. 2010;

3. Mathur P. Hand hygiene: Back to the basics of infection control. Indian J Med Res. 2011;134(11):611-20.

4. Larson E. Skin hygiene and infection prevention: More of the same or different approaches? Clin Infect Dis. 1999;29(5):1287-94. 
5. Nzioka BM, Nyaga JK WE. The relationship between tooth brushing frequency and personal hygiene habits in teenagers.; East Afr Med J. 1993;70:(7):445-448.

6. Sebong PH, Tjitradinata C, Goldman RE. Promoting COVID-19 prevention strategies in student dormitory setting: A qualitative study. J Am Coll Heal. 2021;0(0):1-10. Available from: https://doi.org/10.1080/07448481.2021.1926271

7. Smith PG, Morrow RH R DA. Field Trials of Health Interventions: A Toolbox. 3rd Edition. OUP Oxford Editors. 2015. Chapter 13, Preliminary Studies and Pilot Testing.

8. Rachmawati IN. Pengumpulan Data Dalam Penelitian Kualitatif: WaRachmawati, I. N. (2007). Pengumpulan Data Dalam Penelitian Kualitatif: Wawancara. Jurnal Keperawatan Indonesia, 11(1), 35-40. https://doi.org/10.7454/jki.v11i1.184wancara. J Keperawatan Indones. 2007;11(1):35-40.

9. Ratimanjari NG, Yolanda H. the Relation Between Personal Hygiene and Enterobius Vermicularis Infection Among Children Aged 2-10 Year in Rumah Susun Penjaringan. Damianus J Med. 2019;18(2):80-6.

10. Tangade P, Batra M, Tirth A, Ravishankar T, Shah AF, Pal S. Dental Caries Status of Institutionalized Orphan Children from Jammu and Kashmir, India. Int J Clin Pediatr Dent. 2016;9(4):364-71.

11. Kemensos RI. Perilaku hidup bersih dan sehat (phbs) penguatan kapabilitas anak dan keluarga. Penguatan Kapabilitas Anak dan Keluarga. 2020. 1-14 p.

12. RI. Peraturan Menteri Kesehatan Repubik Indonesia Nomor 41 Tahun 2014 tentang Pedoman Gizi Seimbang. Lincolin Arsyad. 2014;3(2):1-46. Available from: http://journal.stainkudus.ac.id/ index.php/equilibrium/article/view/1268/1127

13. Kemenkes RI. Panduan Cuci Tangan Pakai Sabun. Kesehat Lingkung. 2020;20. Available from: https://kesmas.kemkes.go.id

14. Taufiq A, Maulana FM. Sosialisasi Sampah Organik dan Non Organik serta Pelatihan Kreasi Sampah. J Inov dan Kewirausahaan. 2015;4(1):68-73. 